\title{
Selection of the Cross-Section Design for the LHC Main Dipole
}

\author{
P. Fessia, D. Perini, S. Russenschuck, Cl. Voellinger, R. Vuillermet and C. Wyss \\ CERN, Geneva, Switzerland
}

\begin{abstract}
With the aim of selecting the most suituble design for the series production of the LHC nain dipoles, several possill]e conligurations were analysed with respect to admissible component tolerances and structural stability, field level, field quality, number and weight of parts. Two alternatives designs, featuring common collars made out of aluminium alloy and austenitic steel, respectively, were finally compared in detail. Although botli designs are almost equivalent at nominal conditions, the austenitie stecl collar structure turned out to be far less sensitive to components dimensional variations. This paper reports the main results of the above evaluations, which lead to the ehoice of austenitic steel collars for the LHC main dipoles.
\end{abstract}

\section{INTRODUCTION}

The design of the LHC two-in-one main dipole magnets [1] has to satisfy stringent requirements in view of their successful series manufacture and subsequent operation in the LHC. Their structure must, up to above the ultimate field of 9 $T$ and in spite of electromagnetic forces reaching $400 \mathrm{t} / \mathrm{m}$. prevent any systematic coil movement causing quenches. This aspect is particularly important for magnets operated at $1.9 \mathrm{~K}$, where materials show no practical heat eapacity and any energy dissipated must be removed yia the superfluid helium. $\Lambda$ predictable and controllable structure is required also to achieve the required lolerances on field quality of $a$ lew $10^{-4}$. The component design and assembly must nevertheless allow for tolerances achievable in a cost effective way, to be suitable for magnet series production at an affordable price. We evaluated the behaviour of four difforent dipole cross-section designs in terms of: a) coil prestress during and after collaring, after welding of the shrinking cylinder, after cool-down to $1.8 \mathrm{~K}$ and during operation up to $9 \mathrm{~T}$, b) strength and distribution of the mating forces within the dipole structural elements; c) sensitivity to the tolerances of the geonetry of collars and laminations, and their assenblics; d) sensitivity to variations of coil pre-stress; e) deformation of the collar cavity after asscmbly, cool-down, and during magnet operation; t) fjeld quality; g) guantities of materials and components. As result of this evaluation, a design was selected for series manufacture.

\section{Possible Magnet Cross-SfCtons}

Four different two-ju-one dipole cross-section designs, with the main features below, were considered:

A. double racetrack aluminum alloy (AA) collars, fitted with a magnetic insert (Fig. 1)

B. double AA collar, without magnetic insert (Fig. 2)

C. as above, but with austenitic steel (AS) collars

D. AS separated collars (Fig. 3)

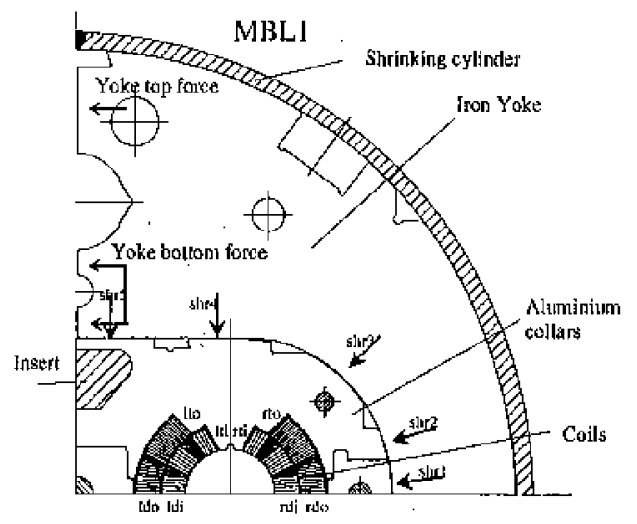

Fig. 1, Design $A$,

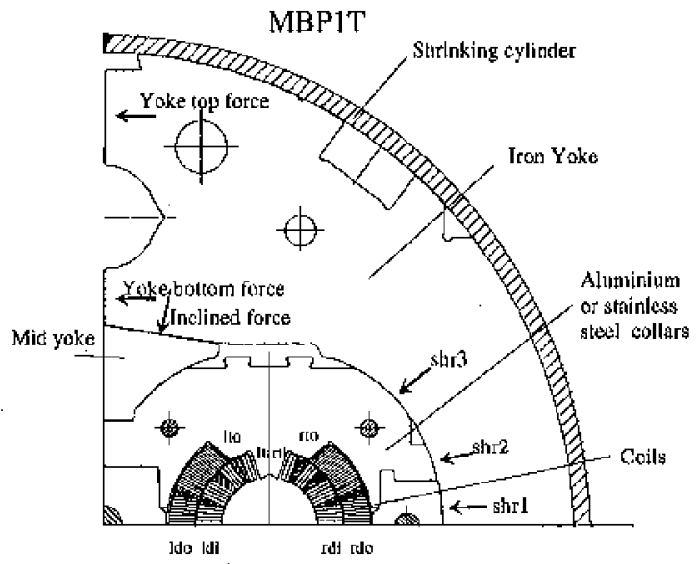

Fig. 2. Designs B (AA collars) and C (AS collars).

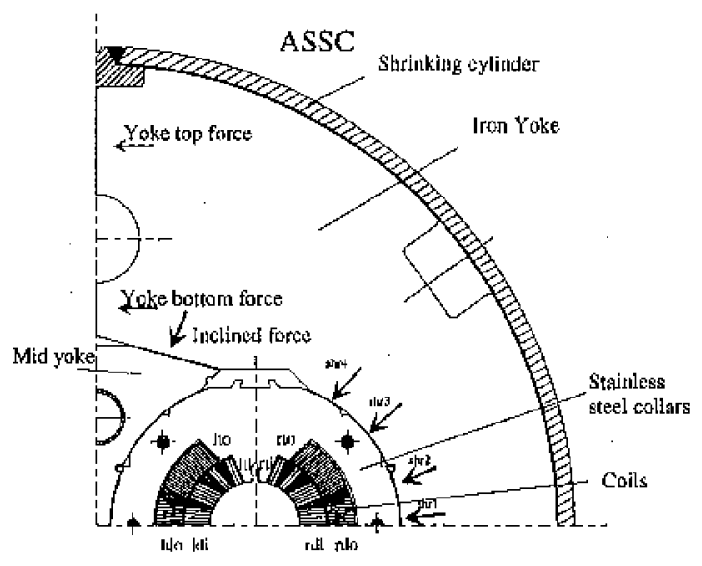

Fig.3. Destgn D. 
These structures present essentially four main components, the behaviour of which must remain matched from assembly at room temperature (RT) to cool-down at $1,9 \mathrm{~K}$ and operation up to a magnetic induetion of $9 \mathrm{~T}$ :

1) the coils; their assembly pre-stress at RT, later removed by the action of the electromagnetic forces at cold, causes the vertical dimensions of the collated coils to vary from $0.3 \mathrm{~mm}$ to $0.15 \mathrm{~mm}$, depending on collar material and design prestress;

2) the collars; the difference in thermal contraction of their material with respect to linat of the coils determines the values of coil pre-stress during collaring and after collaring necessary to achicve the design pre-stress at $1.9 \mathrm{~K}$,

3) the vertically split yoke, always showing a gap before the assembly of the cold mass; the size of this gap and its presence or absence after the welding of the shrinking cylinder, depend on the difference in thermal contraction between the yoke and the collar material;

4) the slutinking cylinder, which assures, by its difference in thermal contraction with respect to that of the yoke, the presence of the mating forces between the yoke halves necessary to take up the e.m. lorces transmitted via the collars and to guarantee the mechanical stability of the structure, and hence limit coil deformations.

\section{Finite Element MOdELs, Optimization, Results}

Four, 2-D models were meshed and the plane-stress option was used for the elenents. It is possible to simulate the collar structures by creating two liyers of a $0.5-\mathrm{mm}$ thick mesh. For the coils, iron yoke, cylinder, insert and locking rods a $1-\mathrm{mm}$ thick layer was meshed. The pre-stress of the coils is imposed by giving an interference at the intorfaces between the collars and the coil. The external cylinder pre-stress is also simulated by giving an interference between the iron yoke and eylinder. The geometry is modeled at room temperafure and in nondeformed conditions, i.e. the dimension used in the model are for parts at their nominal size. The areas were meshed using two-dimensional lincar elements (plane 42) and contact surfaces with threc-dimensional contact elements (contac 52). Further information concerning these elements is available from the ANSYS manuals [2]. Magnet operation is simulated by loading the coils with the elcctro-magnetic forces computed with the same code. Iron saturation was taken into account No friction was considered between the different components in case of relative displacements. The effect of friction was later computed for the B and C designs only [3]. The mesh considers a one-quarter strueture (with appropriate boundary conditions for the simulation of two layers of coltars).

Each of the above cross-sections was optimised, so as to:

a) provide the design coil pre-stress at cold, avoiding at the same time unsafe stresses during collaring, welding of the shrinking cylinder under the assembly press and after assembly. Average compressive values above $130 \mathrm{MPa}$ maintained for more than a few minutes can be dangerous for the coil insulation (creep); b) provide between the yoke halves balanced mating forces larger than the e.m. forces generated during magnet excitation, so as to avoid displacements and instabilities of the mechanical structure;

c) maintain contact between the collared coils and the yoke, in the vertical plane for the whole cxejtation range, so as to stiffen the dipole structure, and in the horizontal plane preferably also for the whole excitation tange, so as to avoid coil deformations during magnet excitation.

The detailed description of the behaviour of the designs $A$. $B, C$ and $D$ from assembly to high field operation is given in [4]. For the four designs, Table I, provides a summary of the layer pre-stresses; Table II gives the size of the open vertical yoke gaps prior to welding of the shrinking cylinder; Tables III and IV show the fevel of the mating forces. It can be seen from the $2^{\text {Tid }}$ column for each desing of Table I, that with doucle collars, the layers "contral" sides (Ido, Idi in Fig, 1) are less prestressed than the layers "Tateral" sices (rdo, rdi in Fig. 1). This effeet stems from the different width (and bence mechanical strength) avariable for the collars central and lateral legs, fixed by the choice of the $194 \mathrm{~mm}$ distance between beam axis and by the iron yoke optimisation (ficld Jevel and quality). A $5 \mathrm{MPa}$ prestress unbalance leads to a leftrigth asymmetry of the layers azimuthal lengths of about $0.025 \mathrm{~mm}$. This elfect is less pronounced for AS collars and does not occur with separate AS collars.

Table II shows that prior to the welding of the shrinking cylinder, AS collars require a vertical yoke gap 3 to 4 times smaller then AA collars. This smaller gap can be safely closed, without damaging the coils, by the force applied by the cold mass assembly press first and subsequently by the weldments of the shrinking cylinder half-shells.

From Table III it can be seen that for design B, with respect to the A one: a) the vertical "inclined force" (or "shrs" for design A) between yoke lamination and insert is at cold and during powering (hree times higher, leading to an enhanced stiffness of the whole structure; b) the "yoke bottom" force at $9 \mathrm{~T}$ is also about three times higher.

Comparing the figures in Tables III and IV, it can be seen that, for a same stress levol in the shrinking cylinder after its welding, the yoke gap is closed (presence of mating forces "yoke top" and "yoke bottom") for designs $\mathrm{C}$ and $\mathrm{D}$. featuring AS collars. As a consequence, at $2 \mathrm{~K}$ the azimuthal stress in the cylinder is $65 \%$ higher than in designs $A$ and $B$ with AA collars, leading to high horizontal and vertical mating forces between yoke elements up to $9 \mathrm{~T}$.

TABLE I

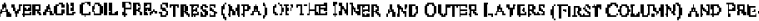

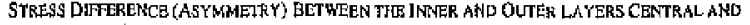

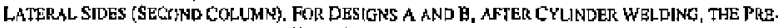

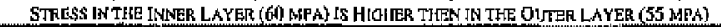

\begin{tabular}{lcccccc}
\hline Design & \multicolumn{2}{c}{ A, B } & \multicolumn{3}{c}{ C } & \multicolumn{3}{c}{ D } \\
\hline At collaring & 90 & 0 & 87 & 0 & 100 & 0 \\
After collaring & 45 & 5 & 65 & 2 & 55 & 0 \\
Alter wolding & $60 / 55$ & 5 & 70 & 2 & 60 & 0 \\
$\mathrm{~T}=2 \mathrm{~K}, \mathrm{~B}=0 \mathrm{~T}$ & 45 & 5 & 40 & 2 & 30 & 0 \\
$\mathrm{~T}=2 \mathrm{~K}, \mathrm{~B}=8.3 \mathrm{~T}$ & 5 & 1 & 5 & 0 & 2 & 0 \\
$\mathrm{~T}=2 \mathrm{~K}, \mathrm{~B}=9 \mathrm{~T}$ & 0 & 0 & 0 & 0 & 0 & 0 \\
\hline
\end{tabular}


TABLE II

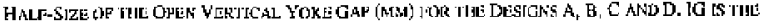

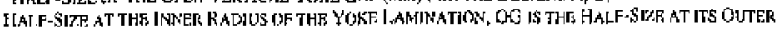

\begin{tabular}{ccc}
\hline Design & OG & IG \\
\hline A & 0.657 & 0.482 \\
B & 0.570 & 0.430 \\
C & 0.240 & 0.130 \\
D & 0.085 & 0.085 \\
\hline
\end{tabular}

T'ABLE III

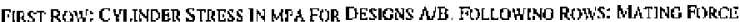

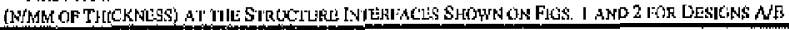

\begin{tabular}{lcccc} 
Localion & $\mathrm{T}=293 \mathrm{~K}$ & $\mathrm{~T}=2 \mathrm{~K}$ & $\mathrm{~T}=2 \mathrm{~K}$ & $\mathrm{~T}=2 \mathrm{~K}$ \\
& $\mathrm{~B}=0 \mathrm{~T}$ & $\mathrm{~B}=0 \mathrm{~T}$ & $\mathrm{~B}=8.3 \mathrm{~T}$ & $\mathrm{~B}=90 \mathrm{~T}$ \\
\hline Cylitider & $159 / 154$ & $206 / 185$ & $200 / 185$ & $207 / 184$ \\
Yoke top & $0 / 0$ & $1093 / 469$ & $1097 / 480$ & $1071 / 468$ \\
Yoke bottom & $0 / 0$ & $818 / 1 / 02$ & $208 / 42 \mathrm{I}$ & $1 / 4 / 300$ \\
Shrs/Inclined & $607 / 594$ & $83 / 460$ & $167 / 58 \mathrm{I}$ & $210 / 616$ \\
Shr L & $410 / 287$ & $52 / 6$ & $418 / 382$ & $693 / 604$ \\
Shr 2 & $602 / 607$ & $1 / 4 / 215$ & $374 / 52 \mathrm{E}$ & $303 / 423$ \\
Shr 3 & $1342 / 1544$ & $0 / 0$ & $0 / 0$ & $0 / 0$ \\
\hline
\end{tabular}

TABLE IV

FTAST ROW: CYLJNDER S TRESS IN MPA FON DESIGNS CJD. FOLLOHING ROWS: MATING FOKCE

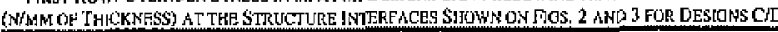

\begin{tabular}{lcccc} 
Locatiot & $\begin{array}{c}\mathrm{T}=293 \mathrm{~K} \\
\mathrm{~B}=0 \mathrm{~T}\end{array}$ & $\begin{array}{c}\mathrm{T}=2 \mathrm{~K} \\
\mathrm{~B}=0 \mathrm{~T}\end{array}$ & $\begin{array}{c}\mathrm{T}=2 \mathrm{~K} \\
\mathrm{~B}=8.3 \mathrm{~T}\end{array}$ & $\begin{array}{c}\mathrm{T}=2 \mathrm{~K} \\
\mathrm{~B}=9.0 \mathrm{~T}\end{array}$ \\
\hline Cylinder & $15 / / 144$ & $320 / 322$ & $321 / 326$ & $329 / 326$ \\
Yoke top & $102 / 358$ & {$[449 / 1645$} & $1393 / 492$ & $1571 / 149 \mathrm{I}$ \\
Yoke botlom & $57 / 75$ & $1408 / 1340$ & $937 / 716$ & $888 / 716$ \\
Jrclined & $622 / 722$ & $396 / 651$ & $531 / 985$ & $557 / 985$ \\
Shr 1 & $167 / 228$ & $0 / 57$ & $200 / 452$ & $292 / 577$ \\
Shr 2 & $689 / 145$ & $28 / 0$ & $356 / 325$ & $439 / 224$ \\
Shr 3 & $606 / 225$ & $0 / 0$ & $0 / 25$ & $0 / 0$ \\
Shr 4 & $0 / 459$ & $0 / 0$ & $0 / 0$ & $0 / 0$ \\
\hline
\end{tabular}

TABLE V

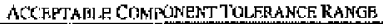

\begin{tabular}{|c|c|c|}
\hline Design & Horizontal axis & Vertionl nxis \\
\hline$A / B$ & $\pm 0.1 \mathrm{~mm}$ & $\pm 0.1 \mathrm{~mm}$ \\
\hline $\mathrm{C} / \mathrm{D}$ & $\pm 0,2 \mathrm{~mm}$ & $\pm 0.3 \mathrm{~mm}$ \\
\hline
\end{tabular}

\section{SENSITHITY ANALYSIS}

Calculations were made to assess which structure is most robust with regard to components and assembly tolerances (hence more appropriate for serics manufacture), and to assess the stability of the geometry of the collar cavity.

\section{A. Effect of Dimensional Tolerances}

The mechanical behaviour of a dipole structure is governed by the geometry of its components (precise to $\pm 0.02 \mathrm{~mm}$ at best) and their subassemblies (precise to $\pm 0,04 \mathrm{~mm}$ at best). The determinant factors are the tolerances of the dimensions of the fine-blanked collars, laminations and inserts and of the coltared coils. The dimensions of the latter depend on coil pre-stress (a variation of $\pm 5 \mathrm{MPa}$ coil pre-siress changes the yertical dimensions of AA and AS collars by \pm 0.05 and $\pm 0.02 \mathrm{~mm}$, respectively).

In the course of assembly, tolerances add up and result in a gap or an interference among components. Tolerances along the horizontal axis lead to an overall tolerance of the vertical yoke gap. The size of this gap governs the strength of the maling forces "yoke top", yoke bottom" and "Shr 1". Tolerances along the vertical axis lead to an overall tolerance of the match between yoke halves and the insert ("inclined force"). The presence of vertical mating forces is essential to maintain the structural stiffness, especially at high field, where the vertical dimensions of the collared coil decrease (depending on collar material) because of the tunloading of the coil pre-stress by the electro-magnetic forces.

The overal? horizontal and vertical tolerances along the cross-section axis were scanned systematically by varying one dimension at atime, the allowable range being defined as the one within which the various mating forces are always positive tp to $9 \mathrm{~T}$. The results are given in Table $\mathrm{V}$, showing that the higher strength (and hence smaller deformation) and smaller thermal contraction of AS collars with respect to AA ones, allow for a wider tolerance band for components and their assombly.

Following the work presented in this paper, further FEM computations were carried out [5], exp]oring at a same time the impact on structural behaviour of the tolerances of several components, as actually observed in the course of model and prototype work, using a statistical approach. The outcome clearly showed that for a large series production, only AS collars can reliably provide the necessary structural stability of the two-in-one LHC main dipole magnet.

\section{B. Deformation of the Collar Cavity}

The hotizontal inward displacement of the dipole aperture centre at assembly, cooldown and operation at $8.3 \mathrm{~T}$ was also computed with the FE models, the results is shown in Table VI,

It can be scen that the relative collar movements are minimum for the designs with AS collars.

Other results reported in [4] show that the radial and arimuthal deformation of a collar with respect to its theoretical chreular shape are minimum with AS collars, providing a better stability of field quality.

TADLE VI

\begin{tabular}{|c|c|c|c|}
\hline Design & $\begin{array}{c}\mathrm{T}=293 \mathrm{~K} \\
\mathrm{~B}=0 \mathrm{~T}\end{array}$ & $\begin{array}{l}\mathrm{T}=2 \mathrm{~K} \\
\mathrm{~B}=0 \mathrm{~T}\end{array}$ & $\begin{array}{c}\mathrm{T}=2 \mathrm{~K} \\
\mathrm{~B}=8,3 \mathrm{~T}\end{array}$ \\
\hline$A$ & 0.09 & 0.42 & 0.39 \\
\hline B & 0,06 & 0.40 & 0,37 \\
\hline$c$ & 0.02 & 0.23 & 0.24 \\
\hline $\mathrm{D}$ & 0,04 & 0,26 & 0.24 \\
\hline
\end{tabular}


TABLE VII

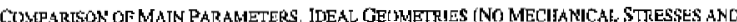
TIIERMAT, SHRINKAGLY).

MULTROT.AR COLFONENTS IN $10^{-4}$ UNATS AT R $=17 \mathrm{MMM}$

\begin{tabular}{|c|c|c|c|c|}
\hline & \multicolumn{2}{|c|}{ Design C } & \multicolumn{2}{|c|}{ Design D } \\
\hline Yoke Indius & \multicolumn{2}{|c|}{$26.5 .5 \mathrm{~mm}$} & \multicolumn{2}{|c|}{$270 \mathrm{~mm}$} \\
\hline I $(A)$ at 8.36 & \multicolumn{2}{|c|}{$11772 \mathrm{~A}$} & \multicolumn{2}{|c|}{$11500 \mathrm{~A}$} \\
\hline Bss & \multicolumn{2}{|c|}{$9.68 \mathrm{~T}$} & \multicolumn{2}{|c|}{$9.75 \mathrm{~T}^{\prime}$} \\
\hline Field oluality & inj & nom & inj & nom \\
\hline Quadrupole & 0.64 & -0.82 & -0.06 & 0.03 \\
\hline Sextupole & 5.78 & 6.18 & 11,00 & 11.44 \\
\hline Octupole & 0,22 & 0.06 & 0.00 & -0.18 \\
\hline Decapole & -0.91 & -0.91 & $-1,14$ & -1.02 \\
\hline
\end{tabular}

\section{FJELD LEVEL AND QUALITY}

Following the results presented so far, AS collars were selected as baseline design. To chose between designs $\mathrm{C}$ and D, they were optimised [6] from the point of view of field level and quality. The coil geometry considered was the 6block geometry already validated by extensive model work [7] and for which 15-m-long tooling was being manufactured by three firms in charge of prototype work. The optimisation objectives were: a) maximum short-sample field Bss; b) smail quadrupole and octupole field components at injection fjeld level; c) low variation of quadrupole, sextupole and octupole components from injection to nominal ficld level d) low sensitivity to tolerances of the yoke geometry e) small yoke outer radius. The optimisation led for design D to an insert shape slightly different from the one shown in Fig. 3, featuring a drop-shaped hole instead of a tound one, to roduce the quadrupole component at high ficld. Main parameters are shown in Table VII.

It can be scen from the above that, with respect to design $C$, design $D$ requires a marginally larger yoke radius, achieves nominal ficld at $2.3 \%$ smaller current (thanks to the larger contribution of the yoke), has to within $0.7 \%$ the same short sample field, presents a sextupole component higher by about 5 units (requiring a coil redesign to satisfy LHC beam optics) and finally shows (for an ideal geometry) at injection field practically no quadrupole and octupole components (the iron insert acts as a perfectly symmetric screcn between the two apertures). Concerning field quality, it is to be noted, however, that the quadrupole and octupole components present at injection ficld with the $\mathrm{C}$ design do not constitute a difficulty [8].

\section{QuANTITIES OF MATERIAL AND COLlaRs}

Designs $\mathrm{C}$ and $\mathrm{D}$ are compared in Table VIII concerning quantity of collar raw material and collar number per magnet unit.

TABLE WIII

\begin{tabular}{lcc} 
AUSTENITIC STCEL QLARTITY AND COLLAR NUMBER PER DIPOLL UNT \\
& Design C & Design D \\
\hline Austeritic stcel & $8770 \mathrm{~kg}$ & $6355 \mathrm{~kg}$ \\
Number of collars & 9400 & 18800 \\
\hline
\end{tabular}

For design D, the larger number of collars to be fineblanked partially compensates the lower cost of the raw material. This cost difference is estimated at below $2 \%$ of the cold mass value. Cost variations resulting from the further handling of different numbers of collars are not considered here.

\section{CONCLUDING REMARKS}

The considerations made in Sections III and IV lead to the choice of AS as collar material. The merits of this choice are: a) the required structural bebaviour can be achieved with realistic components tolerances, making series production possible at affordable conditions; b) the yoke halves can be made to mate (no gap) after assembly at room temperature. (Experience with AA collars has shown that such a gap is difficult to control within the required tolerance of \pm $0,05 \mathrm{~mm}$ ).

The comparison in terms of magnetic performance and cost of collars shows a matginal advantage for design $D$ (separate collars). The implementation of the latter would however regujre the redesign of already available 6-block coil destgn, of winding, curing and collaring tooling, with its inherent costs and time schedules. It was thereforte chosen not to depart from the combined collar design. Strong AScotnbined collars entail only minor changes to existing tooling and drawings. Moreover, they minimise the coupling between collared coils and cold mass assembly, so as to make field quality and cold mass behaviour only weakly dependent on assembly history, which is a positive feature for a large series production.

\section{REFBRENCES}

[1] The Large Hadion Collider CERN/AC/95-05 (LHC), Oetouer 1995

[2] Arisys User's Manual for Revision \$.4, Huston 1997. Swanson Analysis Syste Inc.

[3] M. Bajko, P.Fessin, D.Perith, "FEM computations about the effect of [riction in two LHC main dipole structures", this Conference.

[4] D.Perini, R.Vuillemet. C.Wyss, "Comparative study of different designs of the mochanical structure of the LHC main dipoles", LHC Report unpublished.

[5] M. Bajko, P.Fessia, D.Perini, "Statistical sudies of the robustness of the LHC main dipole mechanical strueture", this Conf.

[6] SRussenschuck, "ROX]E: the routine for the optinization of magnet Xsections, Inverse feeld calculation and coil ond design ${ }^{\text {rt }}$. Proc. of the $1 \mathrm{st}$ Int, Roxic Users Meeting and Workshop, Yellow Repot CERN 99-01, ISBN 92-9083-140-5.

[7] N. Andreev et al, "Performance of fiye and six block coil geometries in short superconlueting dipole models for the LHC", PAC 99, Now York [8] J.P.Koutchonk, "The LHC dynamic aperture", PAC99, New Yotk. 